\title{
A Influência dos Índices Socioeconômicos e Contábeis no nível de Transparência Eletrônica dos Estados Brasileiros sob a ótica da Teoria da Escolha Pública
}

The Influence of Socioeconomic and Accounting Variables on the Level of Electronic Transparency of the Brazilian States under the perspective of the Public Choice Theory

La Influencia de los Índices Socioeconómicos y Contables en el nivel de Transparencia Electrónica de los Estados Brasileños bajo la óptica de la Teoría de la Elección Pública

\author{
Clóvis Fiirs \\ Doutorando em Contabilidade pela Universidade Regional de Blumenau-SC \\ Professor Colaborador departamento de Contabilidade \\ http://lattes.cnpq.br/1052258525837261 \\ https://orcid.org/0000-0002-9415-104X \\ cfiirst@gmail.com
}

Universidade Regional de Blumenau-sc - Departamento de contabilidade Rua Antônio da Veiga, n. 140 - Sala C 202 - Bairro Victor Konder - Caixa Postal 1507 - CEP: 89.012-900 - Blumenau/SC - Brasil E-mail: cfiirst@gmail.com - Fone: (47) 3321-0565

Juliano Francisco Baldissera Mestre em Contabilidade pela Universidade Estadual do Oeste do Paraná Professor Colaborador departamento de Contabilidade da Universidade Estadual do Norte do Paraná http://lattes.cnpq.br/5799184103591305 https://orcid.org/0000-0003-1592-5906 Juliano.baldissera@hotmail.com

Estella Beatriz Martins Graduada em Ciências Contábeis pela Universidade Estadual do Oeste do Paraná Estudante http://lattes.cnpq.br/0898143200907452 https://orcid org/0000-0002-4402-3509 bia182delonge@hotmail.com

Suellen Amabile Agnoletto Nascimento Graduada em Ciências Contábeis pela Universidade Estadual do Oeste do Paraná Estudante http://lattes.cnpq.br/7738606006270031 https://orcid.org/0000-0001-7565-9182 suellen_amabile@hotmail.com

Resumo: O estudo tem como objetivo analisar a influência de variáveis socioeconômicas e contábeis no nível de transparência eletrônica dos estados brasileiros, após a LAl, sob a ótica da Teoria da Escolha Pública. Para tanto, utilizouse dos dados anuais de 2011 a 2015 , em que foi possível estimar uma regressão linear múltipla com dados em painel. Os resultados indicam que o desenvolvimento estadual, a execução orçamentária corrente, a liquidez e os gastos com pessoal influenciam positivamente o nível de transparência eletrônica dos estados. Essas constatações ressaltam os comportamentos dos gestores públicos pelos pressupostos da Teoria da Escolha Pública. Portanto, esses agentes preocupam-se em disponibilizar informações aos cidadãos quando elas trazem 0 resultado financeiro positivo ao estado. A transparência pública corrobora na mitigação da assimetria de informação entre os gestores públicos e a sociedade.

Palavras-chave: Transparência Eletrônica Estadual, Características Socioeconômicas, Variáveis Contábeis, Teoria da Escolha Pública.
Abstract: The study aims to analyze the influence of socioeconomic and accounting variables on the level of electronic transparency of Brazilian states after the Freedom of Information Act (FOI) from the perspective of the Public Choice Theory. Thus, we used the annual data from 2011 to 2015, in which it was possible to estimate a multiple linear regression with panel data. The results indicate that state development, current budget execution, liquidity and staff costs positively influence the level of electronic transparency of the states. These findings highlight the behavior of public managers by the assumptions of Public Choice Theory. Therefore, these agents feel the need to provide citizens with information when they bring the positive financial result to the state. Public transparency corroborates the mitigation of information asymmetry between public managers and society.

Keywords: State Electronic Transparency, Socioeconomic Characteristics, Accounting Variables, Public Choice Theory.
Resumen: El estudio tiene como objetivo analiza la influencia de variables socioeconómicas y contables en el nivel de transparencia electrónica de los estados brasileños después de la LAI bajo la óptica de la Teoría de la elección pública. Para ello, se utilizó de los datos anuales de 2011 a 2015, en los que fue posible estimar una regresión lineal múltiple con datos en panel. Los resultados indican que el desarrollo estadual, la ejecución presupuestaria corriente, la liquidez y los gastos de personal influyen positivamente en el nivel de transparencia electrónica de los estados. Estas constataciones resaltan los comportamientos de los gestores públicos por los presupuestos de la Teoría de la elección pública. Por lo tanto, estos agentes se preocupan en proporcionar información a los ciudadanos cuando éstos traen el resultado positivo financiero al estado. La transparencia pública corrobora en la mitigación de la asimetría de información entre los gestores públicos y la sociedad.

Palabras clave: Transparencia Electrónica Estadual, Características Socioeconómicas, Variables Contables, Teoría de la Elección Pública.

\section{INTRODUÇÃO}

O avanço acelerado da tecnologia e o crescente número de pessoas com acesso fácil à internet ao longo dos últimos anos, notados pela intensa utilização das Tecnologias de Informação e 
Comunicação (TICs), fez com que os gestores públicos se obrigassem à adequação dessa evolução. Por esse motivo, criaram uma forma de os cidadãos terem acesso às informações necessárias e relevantes da gestão governamental, a fim de constituir uma sociedade mais democrática, tendo em vista que na Constituição Federal de 1988 existe a provisão do direito de transparência pública dos gestores para com a população, em que todos têm direito de obter informações dos órgãos públicos, sendo de interesse particular ou de interesse coletivo (Constituição da República Federativa do Brasil, 1988).

Acompanhando a tendência internacional, além de já estar disposto na Carta Magna de 1988, foram criados outros mecanismos que fomentaram a transparência no Brasil, quais sejam as Leis Complementares no 101/2000 e no 131/2009. A regulamentação do acesso à informação se deu, finalmente, por meio da Lei no 12.527/2011 (Lei de Acesso à Informação - LAl). Esse tipo de movimento foi visto em diferentes países e foi um importante marco para fortalecer a cultura da transparência no país (Baldissera, 2018).

Pina, Torres e Acerete (2007) indicam a transparência governamental como um componente de prestação de contas. A disponibilização dessas informações para a população simboliza um ato de responsabilidade, que remete ao termo accountability, que, segundo Behn (1998), é uma característica essencial de qualquer abordagem para estruturação do poder executivo, e em caso de sua não utilização, esse sistema é, perante a sociedade, inaceitável.

A Teoria da Escolha Pública, por sua vez, considera que os agentes públicos e econômicos realizam certa perseguição de rendas dentro da sociedade, em suas atividades de fins privados. Dias (2009) ressalta que a principal motivação da escolha pública são os interesses pessoais dos indivíduos. Parte da premissa que o homem é um maximizador de utilidade (Buchanan \& Tullock, 1962), egoísta e racional (Mueller, 1976), o que justificaria as ações dos agentes públicos à frente da gestão pública (Baldissera, 2018).

A racionalidade, segundo Cruz (2010), motiva e influencia a tomada de decisões no ambiente político. Na medida em que um indivíduo racional prevê o impacto de suas ações, este procura abster-se de regras que diminuam os custos de suas escolhas (Buchanan, 2003). E essa racionalidade possibilita a explicação de como os governos tomam suas decisões, de modo que torne possível a compreensão das interações complexas que ocorrem dentro do setor público (Buchanan, 1984).

Costa, Freire, Gartnet e Clemente (2013) criticam tal teoria, uma vez que os resultados políticos e os resultados de mercado se diferem, alegando que tais diferenças não são decorrentes de motivação comportamental dos indivíduos, mas das instituições e de sua estrutura, pelas quais os indivíduos buscam alcançar seus interesses.

Segundo Silva (2004), a transparência na prestação de contas oportuniza o gestor público a comprovar, perante o órgão competente, o uso, o emprego ou a movimentação dos bens, numerários e valores que lhe foram confiados.

Percebe-se que tanto as regras jurídicas quanto as investigações científicas dependem de esforços para tratar sobre transparência e características socioeconômicas e contábeis; portanto, nesse mesmo sentido, a pesquisa estudou como variáveis socioeconômicas e contábeis influenciam nos níveis de transparência eletrônica dos 28 Estados brasileiros, sendo eles 27 unidades federativas e um distrito federal, por não terem sido encontrados artigos que evidenciassem o nível de transparência dos estados brasileiros, após a Lei de Acesso à Informação. Além de preencher essa lacuna, a presente pesquisa tem a intenção de contribuir na discussão relacionada à assimetria de informação existente entre a sociedade e o governo, ao buscar evidências empíricas que abordam essa temática, e corroborar junto ao ente federado em análise (estados e DF) no quesito da transparência pública.

Não suficiente, o estudo, visando o não cumprimento das obrigações por parte dos gestores públicos, busca entender e analisar as decisões políticas por meio da Teoria da Escolha Pública (Public Choice Theory), a qual tem como propósito maior a utilização de elementos econômicos para a análise de fenômenos políticos, com foco no comportamento dos indivíduos relacionados com todo o processo político, sendo na qualidade de agentes públicos, eleitores ou pessoas interessadas nas políticas adotadas.

Diante do exposto, formulou-se a seguinte questão da pesquisa: qual a influência das variáveis socioeconômicas e contábeis no nível de transparência eletrônica dos Estados Brasileiros, após a LAI, sob a ótica da Teoria da Escolha Pública? Alinhado à referida questão, o objetivo do estudo é analisar a influência de variáveis socioeconômicas e contábeis no nível de transparência eletrônica dos estados brasileiros após a LAI, sob a ótica da Teoria da Escolha Pública.

Dessa forma, a triangulação entre as variáveis socioeconômicas e contábeis e a transparência eletrônica justificase e se torna importante, pois tem a finalidade de demonstrar uma possível justificativa ao cumprimento ou descumprimento, de tais procedimentos que caracterizam a transparência eletrônica, conforme se tem observado na literatura anterior (Cruz et al., 2012; Diniz, Martins \& Neves, 2015; Zuccolotto \& Teixeira, 2014; AlcaideMuñoz, Bolívar, \& Hernández, 2016). Estas variáveis evidenciam onde estão as principais falhas nas escolhas públicas dos gestores e ressaltam aspectos da assimetria de informação entre a sociedade e o governo. Logo, a principal contribuição da pesquisa para com a sociedade se faz pela apresentação de tais dados, buscando criar questionamentos que abordem a assimetria entre a sociedade e o Estado.

O presente estudo está delimitado à área da Contabilidade Pública, e o principal assunto é a observação da influência dos indicadores socioeconômicos e contábeis na transparência pública, após a LAI, estudados sob o prisma da Teoria da Escolha Pública. Para tanto, serão analisados os níveis de transparência pública dos 28 estados brasileiros, por meio dos portais de transparência eletrônica de seus órgãos públicos, observando a influência de variáveis socioeconômicas e contábeis - apresentadas detalhadamente na revisão da literatura -, com os dados dos anos de 2011 a 2015. Os dados foram coletados entre 2016 e 2017. 
Este artigo estrutura-se em cinco seções: introdução, revisão da literatura, metodologia, apresentação e análise dos dados e conclusão. A introdução apresenta a contextualização e justificativa do estudo, o problema da pesquisa, os objetivos e a delimitação. A revisão da literatura apresentará os estudos relevantes sobre a transparência pública eletrônica e sobre os indicadores socioeconômicos e contábeis, assim como a respeito da Teoria da Escolha Pública. A metodologia da pesquisa trará os métodos da obtenção de dados, com ênfase na definição da tipologia de pesquisa quanto a seus objetivos, procedimentos e abordagem, a hipótese da pesquisa, os procedimentos de coleta e análise dos dados e as limitações da pesquisa. A seção de análise mostrará os resultados obtidos pela coleta de dados e a interpretação deles. A quinta e última seção contéma conclusão, confirmando ou não as hipóteses levantadas, além da sugestão de temas para novos estudos.

\section{REVISÃO DA LITERATURA}

2.1 Transparência Eletrônica dos portais dos estados brasileiros de acordo com a Lei de Acesso a Informação e a Teoria da Escolha Pública

Nas sociedades democráticas, o acesso à informação e à transparência é representado como um dos direitos humanos fundamentais (Bellver \& Kaufmann, 2005). Corroborando com este argumento, Stiglitz (1999) diz que o acesso à informação pode ser entendido como um direito básico de todo cidadão, sendo dever do governo repassar aos cidadãos as informações existentes, e que essas informações sejam de fácil compreensão.

A transparência é definida como a provisão de informações de modo continuado aos agentes externos interessados, melhorando a compreensão das ações do governo (Meijer, 2013; Porumbescu, 2015). A transparência se constrói a partir de interações entre atores com diferentes perspectivas em um ambiente institucional, as quais mudam a natureza das próprias relações entre os participantes da sociedade e, por isso, alteram como as relações democráticas são concretizadas (Hood \&Heald, 2006; Meijer, 2013; Baldissera, 2018).

Para Sturges (2004), o acesso à informação pública não só diz respeito a informações sobre como o governo age, mas também a políticas que tenham o objetivo de contribuir com o fortalecimento de fóruns plurais de discussões, com instituições que prestem contas à população, com leis de acesso à informação, com proteções à negativa de prestação de informações por parte de órgãos públicos e à liberdade de imprensa. Portanto, torna-se um valor democrático por excelência que sustenta um governo confiável de alto desempenho e responsável (Hood, 2006; Grimmelikhuijsen \& Welch, 2012; Baldissera, 2018).

A Teoria da Escolha Pública, um importante programa de investigação que começou a ser desenvolvido na década de 50, tem como principal argumento o fato de que os indivíduos são motivados pelos interesses próprios (Dias, 2009). Os agentes públicos e econômicos realizariam seus fins privados, e entre estes está a perseguição de rendas dentro da sociedade (Buchanan
\&Tullock, 1962).

O foco da Teoria da Escolha Pública está no comportamento dos indivíduos relacionados com o processo político, abrangendo a qualidade dos agentes públicos, assim como eleitores ou pessoas que possuem interesse nas políticas a serem adotadas. Entretanto, ela sofreu algumas críticas, como a de Tullock, Seldon e Brady (2002), que consideram o nome "escolha pública" enganador para um sistema econômico e político no qual as escolhas do público não são geralmente satisfeitas pela instituição política pública de tomada de decisões coletivas, tendo em vista que as decisões coletivas são tomadas por representantes das pessoas, e não pelas próprias, resultando, assim, em bens e serviços diferentes do esperado pelo povo.

Segundo Cruz (2010), essa teoria tem perspectiva "racional" para inferir sobre as motivações que influenciam a tomada de decisões no ambiente político. Na medida em que o indivíduo racional é capaz de prever o impacto de suas escolhas, Buchanan (2011) alega que ele tentará escolher uma regra de tomada de decisão, visando minimizar os custos esperados que lhe devam incorrer.

Para Cruz (2010), a teoria ajuda a explicar a maneira pela qual os políticos tomam decisões acerca de impostos, despesas, políticas públicas, entre outros. Este ponto torna importante a relação da teoria da escolha pública com a governança eletrônica, na qual podem ser apresentados detalhes importantes sobre as decisões dos governantes a respeito da governança pública e eletrônica.

A gestão pública usa como recurso a governança eletrônica, aplicando, por meio dela, recursos das TICs, utilizados para a melhor qualidade de participação pública do governo. Segundo Mello (2009), a governança eletrônica é composta pelo governo eletrônico e democracia eletrônica, e tem como objetivo o fornecimento de serviços e informações, a fim de promover maior participação cidadã. A administração eletrônica tem o dever de disponibilizar informações e serviços por meio eletrônico, utilizando serviços eletrônicos e prestação de serviço online.

\subsection{A Relação da Transparência Eletrônica dos portais governamentais e indicadores socioeconômicos e contábeis}

A informática foi introduzida na administração pública em meados de 1970. Em um primeiro momento, estava focada apenas na gestão das receitas e despesas, por meio do uso de tecnologias da informação e comunicação (TICs). O desenvolvimento dessas tecnologias possibilitou a ampliação de sua utilização, proporcionando a oferta de serviços aos cidadãos, por exemplo, e segundo Diniz (2005), sua aplicação pela administração pública pode ser dividida em três fases. A primeira delas ocorreu entre os anos de 1970 e 1992, quando o foco era na gestão interna por meio de sistemas de controle e de sistemas estruturadores; a segunda entre os anos de 1993 e 1998, focava nos serviços e informações, com novo conceito de atendimento ao consumidor. A terceira fase de 1999 a 2004, diz respeito aos serviços via internet, cujo marco foi o início do governo eletrônico do estado de São Paulo, com a 
inauguração de uma nova era de portais de serviços ao cidadão.

Prado (2009) destaca a importância do Governo Eletrônico neste marco, apontando seu surgimento logo nos primeiros anos desta evolução junto às agendas governamentais, que buscavam uma maior eficiência do setor público. Segundo o autor, estas agendas, em seguida, ampliaram suas discussões também para os temas de accountability e transparência, que se tornaram cada vez mais presente nas ações do governo eletrônico.

Cabe ressaltar a discussão apresentada por Prado e Loureiro (2007), na qual afirmam que a transparência eletrônica da Administração Pública não atinge a sociedade, uma vez que há pouco acesso dos cidadãos aos portais eletrônicos. Ainda sobre a ineficiência das informações à sociedade, Sartori (2001) descreve que, além da apatia por parte dos cidadãos, há também erros por parte do fornecimento dessas informações pelo governo, que, segundo o autor, alteram sua qualidade e sua confiabilidade. Este autor destaca três desses erros: insuficiência quantitativa, tendenciosidade e pobreza qualitativa. Tais problemas apresentam a necessidade de o governo sempre buscar o aperfeiçoamento das informações prestadas e a clareza desses dados, para, consequentemente, aumentar o interesse dos cidadãos quanto ao acesso e ao conhecimento desse conteúdo. Entretanto, apesar de se entender que as informações disponíveis não tenham qualidade e utilidade, somente a suficiência afetaria a assimetria de informação (Baldissera, Walter, Fiirst, Dall'Asta, 2018).

Um bom nível de transparência pode ser explicado por fatores socioeconômicos, como os apresentados pela receita operacional. Como Cruz, Ferreira e Silva (2012) apresentaram em sua pesquisa, dentre as variáveis socioeconômicas, a receita orçamentária tem associação positiva com o nível de transparência eletrônica. Diniz et al. (2015) também demonstraram que há influência positiva das variáveis Índice de Desenvolvimento Humano (IDH) municipal e IDH renda sobre a transparência da gestão.

Zuccolotto e Teixeira (2014) apresentaram em sua pesquisa que as variáveis fiscais (Receitas Correntes, Déficit/Superávit resultado fiscal do governo - e Endividamento) influenciam positivamente no nível de transparência dos estados brasileiros, ou seja, quanto melhores as condições fiscais do Estado, mais transparente o processo será. Em estudo realizado com os governos espanhóis, Cárcaba-García e García (2010) abordaram a relação da transparência com diversos aspectos socioeconômicos, financeiros e políticos, tendo encontrado uma relação positiva significativa com tamanho, investimentos de capital e competição política, e uma relação negativa significativa com a visibilidade da imprensa.

Alcaide Muñoz et al. (2016) consolidam boa parte da literatura a respeito dos determinantes da transparência pública e confirmam que as variáveis que têm efeito positivo sobre a transparência são aspectos relacionados à condição financeira, transferências intergovernamentais, competição política, tamanho e riqueza municipal. Entretanto, o efeito entre essas variáveis dependeria do contexto em que a pesquisa é desenvolvida, tais como o estilo administrativo e o nível do governo. Por fim, Baldissera (2018) também sinaliza que existe efeito das variáveis socioeconômicas, financeiro-orçamentárias e políticas sobre a transparência pública dos governos locais brasileiros.

De acordo com as evidências de estudos anteriores (CárcabaGarcía \& García, 2010; Cruz, Silva \& Santos, 2010; Cruz et al.,2012; Zuccolotto \& Teixeira, 2014; Diniz et al.,2015; Alcaide Muñoz et al., 2016; Baldissera, 2018), tem-se percebido que os estudos têm abordado diferentes variáveis, entre as quais as variáveis socioeconômicas e contábeis ganham destaque e merecem ser estudadas, principalmente no caso do governo estadual brasileiro. Dessa forma, formulou-se as hipóteses de pesquisa $\mathrm{H} 1$ e H2:

H1: Existe influência positiva entre as condições socioeconômicas e o nível de transparência na divulgação de informações acerca da gestão pública dos estados brasileiros.

H2: Existe influência positiva entre as variáveis contábeis e o nível de transparência na divulgação de informações acerca da gestão pública dos estados brasileiros.

\section{METODOLOGIA}

Os tipos de pesquisa, segundo Beuren (2008), são classificados de acordo com os objetivos, os procedimentos e a abordagem do problema de cada estudo. O que define a tipologia da pesquisa conforme os seus objetivos são os resultados que a pesquisa pretende alcançar, devendo-se analisar as características que cada tipo de pesquisa compreende e a relação desta com o objetivo da pesquisa (Beuren, 2008). Sabendo que o objetivo do presente estudo é analisar a influência das variáveis socioeconômicas e contábeis no nível de transparência eletrônica dos estados brasileiros, após a LAI, sob a ótica da Teoria da Escolha Pública, pode-se considerar este estudo como uma pesquisa descritiva, posto que visa constatar e analisar a relação entre as variáveis estudadas, sem que haja a interferência na realidade apresentada.

Segundo Perovano (2014), o processo descritivo visa à identificação, registro e análise das características, fatores ou variáveis que se relacionam com o fenômeno ou processo. Após a coleta de dados, é realizada uma análise das relações entre as variáveis. Quanto aos procedimentos da pesquisa, utiliza-se da pesquisa documental, pois analisa dados disponibilizados por órgãos públicos, em documentos tais comoregistros, anais, regulamentos, circulares, ofícios, demonstrativos financeiros, todos com acesso público por meio dos portais eletrônicos. De acordo com Gil (2008), a pesquisa documental é semelhante à bibliográfica, mas tem como diferença a natureza das fontes, pois nesta forma, vale-se de materiais que não receberam um tratamento analítico ou que ainda podem ser reelaborados de acordo com os objetivos da pesquisa.

Quanto à abordagem do problema, esta terá a análise dos dados realizada de forma quantitativa, em que se utiliza de técnicas estatísticas, tais como regressão linear múltipla com dados em painel. Segundo Richardson (1989), esse método caracteriza-se pelo emprego de quantificação para coleta e tratamento de informações, utilizando técnicas estatísticas. De acordo com este mesmo autor, esse método é frequentemente utilizado para estudos 
descritivos.

Os procedimentos de coleta e análise de dados são importantes para o andamento da pesquisa. De acordo com Carvalho (1988), a pesquisa documental é realizada a partir de documentos considerados cientificamente autênticos, que apresentam e comparam fatos sociais, indicando suas características, e utilizando-se também de dados estatísticos, elaborados por institutos especializados e confiáveis para a realização de pesquisas.

O Brasil é composto por 28 unidades federativas, sendo 27 estados e um Distrito Federal, representados nesta pesquisa como população e amostra. Para demonstrar estatisticamente a realidade do nível de transparência eletrônica dos estados brasileiros após a LAI, serão utilizados dados de portais eletrônicos, como os sites dos estados, o site da Escala Brasil Transparente (EBT) - $2^{a}$ edição, realizada e publicada pelo portal eletrônico da Controladoria-Geral da União (CGU), que calcula o índice de transparência dos estados de acordo com os dispositivos da LAI. Para as variáveis socioeconômicas, serão utilizados dados e índices do Instituto Brasileiro de Geografia e Estatística (IBGE).

As variáveis contábeis serão elaboradas a partir das fórmulas dos Indicadores de Lourençon (2001), Campello (2003), Ruckert, Borsatto e Rabelo (2002) e Macedo e Corbari (2009). Estes cálculos serão realizados conforme as demonstrações contábeis disponibilizadas no site da Secretaria do Tesouro Nacional (STN), referente aos anos de 2011 a 2015. Esse período foi escolhido tendo em vista a limitação de dados disponíveis, principalmente no que se refere ao índice de transparência. Além disso, a análise em um período de cinco anos permite identificar a evolução do comportamento do gestor e das condições financeiras e orçamentárias dos estados.

No quadro 1, a seguir, está apresentado o constructo do estudo, evidenciando a operacionalização do objetivo geral alinhado às variáveis da pesquisa.

Quadro 1 - Variáveis da pesquisa

\begin{tabular}{|c|c|c|c|}
\hline Código & Descrição & Fonte / Ano & Autor \\
\hline \multicolumn{4}{|c|}{ VARIÁVEL DEPENDENTE } \\
\hline \multicolumn{4}{|c|}{ TRANSPARÊNCIA } \\
\hline $\begin{array}{l}\text { Nível de } \\
\text { Transparência } \\
\text { (TRANSP) }\end{array}$ & $\begin{array}{l}\text { Índice de Transparência: o índice toma como base as LC 101/2000, } \\
\text { LC } 131 / 2009 \text {, e Lei no } 12 / 527 / 2011 \text {, bem como outros dispositivos } \\
\text { legais correlacionados com a transparência. Os itens avaliados no que } \\
\text { se refere à transparência são informações sobre receita, despesa, } \\
\text { licitações e contratos, relatórios, serviço de informação ao cidadão } \\
\text { presencial (SIC) e eletrônico (e-SIC), divulgação da estrutura e forma } \\
\text { de contato e, por fim, boas práticas de transparência. }\end{array}$ & $\begin{array}{l}\text { www.combateacorrupcao.mpf } \\
\text {.mp.br } \\
2015\end{array}$ & $\begin{array}{l}\text { Ministério Público Federal } \\
\text { (MPF) }\end{array}$ \\
\hline \multicolumn{4}{|c|}{ VARIÁVEIS INDEPENDENTES } \\
\hline \multicolumn{4}{|c|}{ VARIÁVEIS SOCIOECONÔMICAS } \\
\hline População (POP) & População: Quantidade de habitantes por estado. & $\begin{array}{l}\text { www.ibge.gov.br } \\
2010\end{array}$ & IBGE \\
\hline $\begin{array}{l}\text { Desenvolvimento } \\
\text { Estadual (IFDM) }\end{array}$ & $\begin{array}{l}\text { İndice Firjan de Desenvolvimento Estadual: İndice que calcula o } \\
\text { desenvolvimento socioeconômico dos estados brasileiros, tendo como } \\
\text { base o emprego, renda, educação e saúde. Elaborado pelo Sistema } \\
\text { Firjan. }\end{array}$ & $\begin{array}{l}\text { www.firjan.com.br/ifdm } \\
2011,2012,2013\end{array}$ & FIRJAN \\
\hline $\begin{array}{l}\text { Gestão Fiscal } \\
\text { (IFGF) }\end{array}$ & $\begin{array}{l}\text { Índice Firjan de Gestão Fiscal: Índice construído a partir dos } \\
\text { resultados fiscais dos estados - informações de declaração obrigatória } \\
\text { e disponibilizada anualmente pela Secretaria do Tesouro Nacional } \\
\text { (STN). }\end{array}$ & $\begin{array}{l}\text { www.firjan.com.br/ifgf } \\
2011,2012,2013,2014,2015\end{array}$ & FIRJAN \\
\hline \multicolumn{4}{|c|}{ VARIÁVEIS CONTÁBEIS } \\
\hline $\begin{array}{l}\text { Realização da } \\
\text { Receita } \\
\text { Orçamentária } \\
\quad \text { (IRRO) }\end{array}$ & $\begin{array}{l}\text { Indicador da realização da receita orçamentária: evidencia o grau } \\
\text { de acerto do planejamento e da estimação das receitas, considerando } \\
\text { a receita total realizada e a receita total orçada, sendo: } \\
\qquad I R R O=R T R / \text { RTO } \\
\text { Onde: IRRO = Indicador da realização da receita orçamentária; } R T R= \\
\text { Receita Total Realizada; } R T O=\text { Receita total orçada. }\end{array}$ & $\begin{array}{l}\text { www.siconfi.tesouro.gov.br } \\
2011,2012,2013,2014,2015\end{array}$ & Lourençon (2001) \\
\hline $\begin{array}{l}\text { Execução } \\
\text { Orçamentária } \\
\quad(\text { IEOC) }\end{array}$ & $\begin{array}{l}\text { Indicador da execução orçamentária corrente: evidencia a } \\
\text { capacidade do órgão público em manter suas despesas correntes } \\
\text { através das respectivas receitas correntes para o mesmo período, } \\
\text { sendo: } \\
\qquad I E O C=R C R / D C R \\
\text { Onde: IEOC = Indicador da execução orçamentária corrente; } R C R= \\
\text { Receita corrente realizada; } D C R=\text { Despesa corrente realizada. }\end{array}$ & $\begin{array}{l}\text { www.siconfi.tesouro.gov.br } \\
2011,2012,2013,2014,2015\end{array}$ & $\begin{array}{l}\text { Campello(2003), } \\
\text { Ruckert, Borsatto e } \\
\text { Rabelo (2002) }\end{array}$ \\
\hline $\begin{array}{l}\text { Realização da } \\
\text { Receita Tributária } \\
\quad(\text { IRRT) }\end{array}$ & $\begin{array}{l}\text { Indicador de realização de receita tributária: evidencia a pressão } \\
\text { tributária exercida sobre a riqueza econômica dos estados, } \\
\text { mensurando a receita tributária arrecadada em relação ao PIB } \\
\text { (Produto Interno Bruto): } \\
\qquad I R R T=\frac{R T R}{P I B l} \\
\text { Onde: IRRT = Indicador de realização de receita tributária; } R T R= \\
\text { Receitas tributárias realizadas; } P I B I=\text { Produto interno bruto local }\end{array}$ & $\begin{array}{l}\text { www.siconfi.tesouro.gov.br } \\
2011,2012,2013,2014,2015\end{array}$ & $\begin{array}{l}\text { López e Corrado } \\
\text { (2005) }\end{array}$ \\
\hline $\begin{array}{l}\text { Operações de } \\
\text { Crédito (IOC) }\end{array}$ & $\begin{array}{l}\text { Indicador de operações de crédito: evidencia o montante das } \\
\text { operações de crédito na composição das despesas de capital, sendo: } \\
\qquad I O C=O C R / D C R \\
\text { Onde: OCR = Operações de crédito realizadas; DCR = Despesas de }\end{array}$ & $\begin{array}{l}\text { www.siconfi.tesouro.gov.br } \\
2011,2012,2013,2014,2015\end{array}$ & Alves e Santos (2011) \\
\hline
\end{tabular}




\begin{tabular}{|c|c|c|c|}
\hline & capital realizadas & & \\
\hline $\begin{array}{l}\text { Estrutura de } \\
\text { Capital (IEC) }\end{array}$ & $\begin{array}{l}\text { Indicador de Estrutura de Capital: indica a parcela do passivo total } \\
\text { que é proveniente de terceiros, sendo: } \\
\qquad I E C=\frac{P F+P P}{A T} \\
\text { Onde: } \mathrm{PF}=\text { Passivo Financeiro; } \mathrm{PP}=\mathrm{Passivo} \text { Permanente; } \mathrm{AT}=\text { Ativo } \\
\text { Total }\end{array}$ & $\begin{array}{l}\text { www.siconfi.tesouro.gov.br } \\
2011,2012,2013,2014,2015\end{array}$ & Macedo e Corbari (2009) \\
\hline Liquidez (ILIQ) & $\begin{array}{l}\text { Indicador de Liquidez: indica o comprometimento patrimonial e as } \\
\text { condições de liquidez, sendo: } \\
\qquad I L I Q=\frac{A F}{P F} \\
\text { Onde: } \mathrm{AF}=\text { Ativo Financeiro; } \mathrm{PF}=\text { Passivo Financeiro }\end{array}$ & $\begin{array}{l}\text { www.siconfi.tesouro.gov.br } \\
2011,2012,2013,2014,2015\end{array}$ & Macedo e Corbari (2009) \\
\hline $\begin{array}{c}\text { Grau de } \\
\text { Dependência } \\
\text { (IGD) }\end{array}$ & $\begin{array}{l}\text { Indicador de grau de dependência: indica o grau de dependência da } \\
\text { administração estadual em relação às transferências recebidas, } \\
\text { sendo: } \\
\qquad I G D=\frac{R T r a n s}{R T} \\
\text { Onde: } I G D=\text { Indicador de grau de dependência; } R \text { Trans = Receita de } \\
\text { transferência; } \\
R T=\text { Receita Total }\end{array}$ & $\begin{array}{l}\text { www.siconfi.tesouro.gov.br } \\
2011,2012,2013,2014,2015\end{array}$ & Macedo e Corbari (2009) \\
\hline $\begin{array}{l}\text { Despesas com } \\
\text { Pessoal (IDP) }\end{array}$ & $\begin{array}{l}\text { Indicador de Despesas com Pessoal: Indica quanto das receitas } \\
\text { correntes são comprometidas às despesas com pessoal, sendo: } \\
\qquad I D P=\frac{P e s+E n c}{R C L} \\
\text { Onde: Pes= Pessoal; Enc= Encargos; } \mathrm{RCL}=\text { Receita Corrente Líquida. }\end{array}$ & $\begin{array}{l}\text { www.siconfi.tesouro.gov.br } \\
2011,2012,2013,2014,2015\end{array}$ & Macedo e Corbari (2009) \\
\hline $\begin{array}{l}\text { Despesas com } \\
\text { Investimento (IDI) }\end{array}$ & $\begin{array}{l}\text { Indicador de Despesas com Investimento: Apresenta a relação } \\
\text { entre as Despesas de Investimento e a Receita Corrente Líquida, } \\
\text { sendo: } \\
\qquad I D I=\frac{G I}{R C L} \\
\text { Onde: } \mathrm{GI}=\text { Gastos de Investimento; } \mathrm{RCL}=\text { Receita Corrente Líquida. }\end{array}$ & $\begin{array}{l}\text { www.siconfi.tesouro.gov.br } \\
2011,2012,2013,2014,2015\end{array}$ & Macedo e Corbari (2009) \\
\hline
\end{tabular}

Fonte: Os autores (2017).

Para verificar a influência de características socioeconômicas e contábeis no nível de transparência eletrônica, respondendo ao problema da pesquisa, ao objetivo geral e ainda às hipóteses $\mathrm{H} 1 \mathrm{e}$

$\mathrm{H} 2$, utilizou-se do modelo econométrico abaixo, em forma de regressão linear múltipla com dados em painel. Equação (1):

$$
\begin{aligned}
\text { TRANSP }_{I T}=\beta_{0}+\beta_{1} & \text { POPit } \\
& +\beta_{2} \text { IFDMit }+\beta_{3} \text { IFGFit }+\beta_{4} \text { IRROit }+\beta_{5} \text { IEOCit } \\
& +\beta_{6} \text { IRRTit }+\beta_{7} \text { IOCit }+\beta_{8} \text { ECit }+\beta_{9} \text { LIQit } \\
& +\beta_{10} \text { GDit }+\beta_{11} \text { DPit }+\beta_{12} \text { IDIit }+\epsilon_{t \ldots}
\end{aligned}
$$

As variáveis da equação 1 estão detalhadas no quadro 1 , constructo da pesquisa. Para tratamento, tabulação e análise dos resultados, foram utilizados como ferramentas auxiliares os softwares Stata ${ }^{\circledR}$, versão 14 e Office Excel ${ }^{\circledR}$.

A pesquisa está limitada à observação dos indicadores dos estados brasileiros nos anos de 2011 a 2015, estabelecendo um contexto único. A amostragem não probabilística utilizada não permite a generalização estatística. Tratando-se de uma pesquisa documental, a confiabilidade e fidelidade dos dados se restringem aos que foram obtidos.

\section{APRESENTAÇÃO E ANÁLISE DOS RESULTADOS}

A partir da coleta dos dados, informações para cálculo dos índices, apresentadas nos portais de transparência dos estados brasileiros e dispostas em painel, fez-se a análise por meio da regressão linear múltipla, com baseno modelo econométrico apresentado na seção anterior. A partir desta análise, averigou-se o nível de transparência dos estados em relação aos seus índices socioeconômicos e contábeis, expressos na Tabela 1, e em seguida relacionou-se a Teoria da Escolha Publica aos resultados encontrados.

\subsection{Influências das características socioeconômicas e contábeis no índice de transparência.}

Elaborou-se a Tabela $1 \mathrm{com}$ o propósito de expressar os resultados da regressão prevista na Equação (1), no sentido de verificar a influência das características socioeconômicas (POP, IFDM, IFGF) e contábeis (IRRO, IEOC, IRRT,IOC, IEC, ILIQ, IGD, IDP, IDI) sobre o nível de transparência (TRANSP) dos 27 estados brasileiros. 
Tabela 1 - Influência das características socioeconômicas e contábeis na transparência

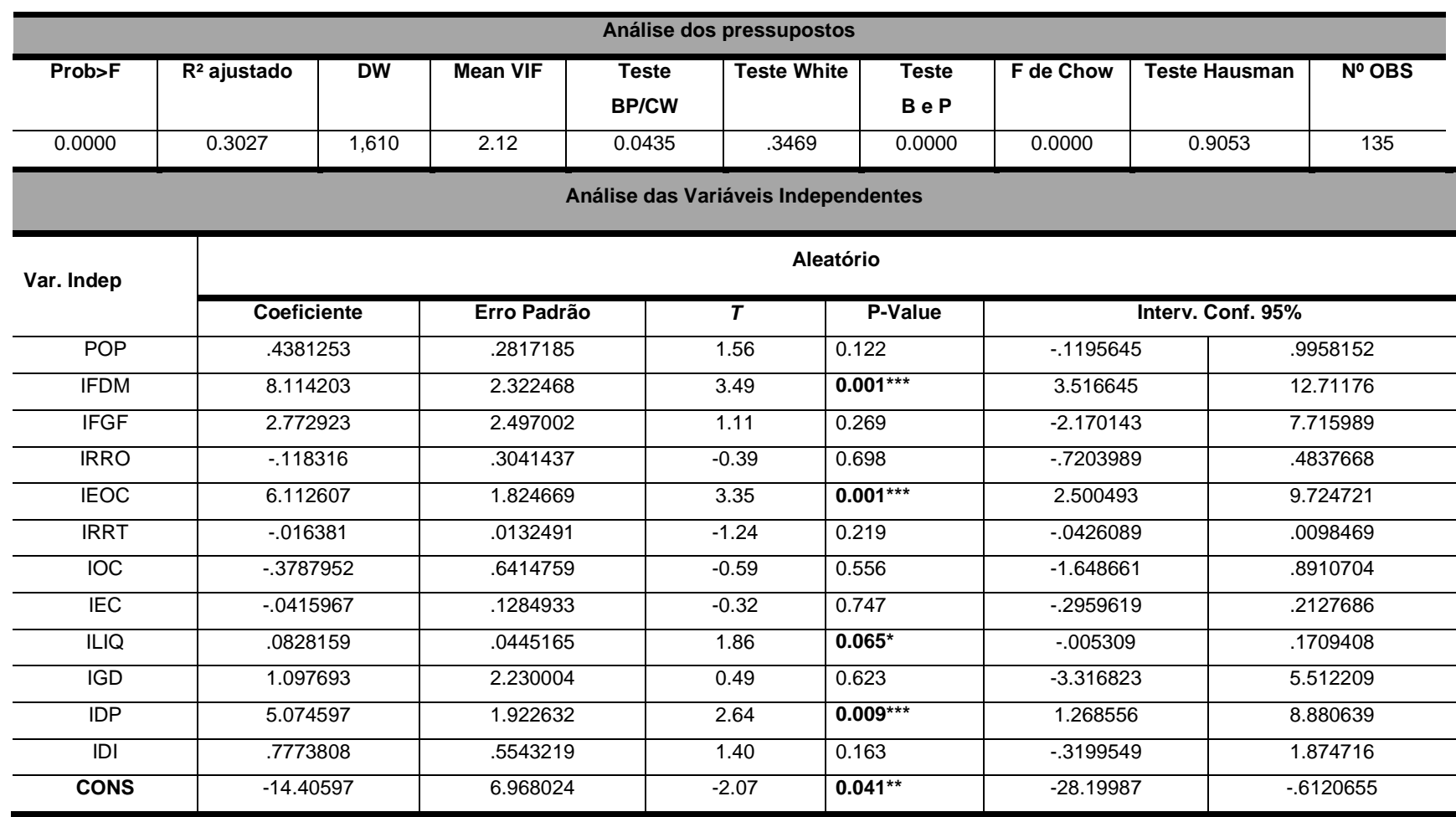

***Significância ao nível de até 1; ** Significância ao nível de até 5; *Significância ao nível de até 10

Legenda: Prob>F: significância do Modelo; R2: poder explicativo do modelo; DW: Durbin-Watson - autocorrelação; Teste BP/CW: Breuch-Pagan/Cook-

Weisberg - teste de heterocedasticidade dos resíduos; Teste White: teste de heterocedasticidade dos resíduos; Teste B e P: BreuschandPagan- verificação da adequação da modelagem em painel; F de Chow: verificação da adequação da modelagem em painel; Teste Hausman: verificação da adequação da modelagem em painel.

Fonte: Os autores (2017)

O teste de Chow indicou que a hipótese nula de que todos os interceptos são iguais (POLS) fosse rejeitada; portanto, o mais recomendado é o modelo com efeitos fixos. O teste de Hausman não rejeitou a hipótese nula de que o modelo de correlação dos erros é adequado (efeitos aleatórios). Assim, com base nesses testes no caso deste estudo, o modelo com efeitos aleatórios é mais recomendado na Equação (1).

Observa-se que a modelagem da Equação (1), composta de 135 observações, foi significante ao nível de 1\% para a amostra desta pesquisa. $\mathrm{O} \mathrm{R}^{2}$ que representa a proporção da variação amostral da variável dependente, explicada pelas variáveis explicativas (Wooldridge, 2003), é de 30,27\%. O modelo não apresenta problemas de autocorrelação, uma vez que o DurbinWatson é 1,610, dentro do limite aceitável (Hill, Judge, \&Griffiths, 2010). Não há problemas de multicolinearidade, conforme indica o teste VIF $(2.12<10)$, medida de quanto a variância de cada coeficiente de regressão estimado aumenta devido à multicolinearidade (Fávero, Belfiores, Silva, \& Chan, 2009). Apesar de o teste de White (0.3469) não indicar problemas, o teste de Breusch-Pagan/Cook-Weisberg (0.0435) indica ter problemas de heterocedasticidade nos resíduos, justificando-se possivelmente pela utilização de alguns outliers na amostra, gerando alguma discrepância entre os dados (Gujarati, 2006); no entanto, para confiabilidade e robustez, aplicou-se a correção robusta de White.

Diante dos pressupostos verificados na Equação (1), procedeu- se o teste da $\mathrm{H} 1$, pela qual se observa que apenas a variável IFDM demonstrou significância ao nível de 10\%, o que demonstra a relação das variáveis socioeconômicas com os níveis de transparência dos estados brasileiros. As demais variáveis não apresentaram significância, o que permite inferir que elas não determinam a variação dos níveis de transparência dos estados. A significância da variável IFDM teve associação positiva, permitindo proceder com a análise, evidenciando a explicação que quanto mais desenvolvido o estado, tendo como base o emprego, renda, educação e saúde, maior é o nível de transparência eletrônica medido pela LAI.

Nos estudos anteriores, como os de Cárcaba-García e García (2010), Cruz et al. (2010), Cruz et al. (2012), Zuccolotto e Teixeira (2014), Diniz et al. (2015), Alcaide Muñoz et al. (2016) e Baldissera (2018), também ficou evidenciada a influência positiva entre as variáveis socioeconômicas com a transparência da gestão.

Já para o teste da H2, observou-se que as variáveis IEOC, ILIQ, IDP demonstraram significância ao nível de 10\%, sendo possível explicar com elas a dependência entre as variáveis contábeis e o nível de transparência. A variável IEOC possui influência positiva sobre o índice de transparência eletrônica, ou seja, diretamente proporcional à transparência. Essa variável apresenta a realização da receita orçamentária, isto é, a capacidade do estado em manter suas despesas correntes através das receitas correntes para 0 mesmo período. Essa evidenciação não foi constatada nos estudos 
anteriores que utilizaram indicadores contábeis em relação ao nível de transparência.

Igualmente, apresentou-se positiva a influência da variável ILIQ, que indica o comprometimento patrimonial e as condições de liquidez do estado, sobre o nível de transparência eletrônica, ou seja, quanto maior o comprometimento patrimonial do estado, maior e melhor é seu nível de transparência. Essa variável não foi evidenciada em nenhum dos estudos anteriores que utilizaram indicadores contábeis para avaliar o índice de transparência eletrônica.

A variável IDP indica o quanto das receitas correntes é comprometido às despesas com pessoal, e a relação significativa entre essa variável e o nível de transparência dos estados, de igual forma às demais, foi positiva e diretamente proporcional, ou seja, quanto mais o estado gasta com pessoal, maior é o seu nível de transparência eletrônica. Tais evidenciações de associação positiva entre os índices contábeis alinham-se aos resultados apresentados por estudos anteriores com a mesma temática.

Portanto, pela regressão linear múltipla foi possível perceber que tanto as variáveis socioeconômicas como as contábeis influenciam no nível de transparência dos 27 estados brasileiros, sendo ambas influenciadoras positivas. Ainda que nem todas as variáveis tenham se apresentado significantes, as variáveis IFDM, IEOC, ILIQ, IDP foram suficientes para explicar o nível de transparência dos estados.

Com tais constatações, foi possível efetuar o teste das hipóteses propostas para o estudo. A primeira afirma que existe influência positiva das variáveis socioeconômicas no nível de transparência; conforme observado nos resultados, o nível de desenvolvimento influencia positivamente a transparência do estado, permitindo a condição de aceite da H1. A segunda hipótese diz que há influência positiva entre as variáveis contábeis e o nível de transparência dos estados, e, observando as que apresentaram significância (IEOC, ILIQ, IDP), foi possível apurar a condição de aceite também da $\mathrm{H} 2$.

\subsection{Discussão das hipóteses e relação dos resultados com a teoria da Escolha Pública}

Conforme já mencionado, o foco da Teoria da Escolha Pública está no comportamento dos indivíduos relacionados com todo o processo político, seja na qualidade de agentes públicos, seja como eleitores, ou pessoas que possuem interesse nas políticas a serem adotadas.

Muller (1989) retrata essa teoria como o estudo econômico da tomada de decisões e a aplicação da economia à ciência política. $\mathrm{O}$ objeto da escolha pública é o mesmo da ciência política: a teoria do estado, as regras eleitorais, o comportamento dos eleitores, os partidos políticos, a burocracia, e assim por diante. No entanto, a metodologia da escolha pública é econômica.

Dessa forma, considerando que os resultados desta pesquisa condicionaram o aceite das hipóteses $\mathrm{H} 1$ e H2, que propunham a existência de influência positiva entre as condições socioeconômicas, as variáveis contábeis e o nível de transparência eletrônica dos portais dos estados, há uma demonstração de que os agentes políticos se preocupam em aumentar a transparência de suas decisões. Nesse sentido, depreende-se que esses agentes disponibilizam mais informações quando estão em uma condição financeira boa, sinalizando competência e legitimando as suas escolhas públicas perante os cidadãos.

A variável IFDM capta o grau de desenvolvimento no que se refere à saúde, educação, emprego e renda. A relação positiva desta variável se justifica, uma vez que uma população bemeducada exige mais informações das administrações públicas (Tolbert\&Zucker, 2008) e também quer saber se os seus impostos estão sendo gastos de forma efetiva (Alcaide-Muñoz et al., 2016; Baldissera, 2018).

Os entes estaduais brasileiros buscam se mostrar mais transparentes quando estão em uma situação financeira adequada. A situação financeira é retratada pelas variáveis IEOC e ILIQ. O resultado obtido demonstra que, quando está alta a capacidade do governo estadual em cumprir com suas promessas de pagamentos, isso reflete sua credibilidade financeira, e isso faz com que os gestores públicos sejam encorajados a divulgar mais informações, de modo que suas ações sejam monitoradas (Cárcaba \& García, 2008, Baldissera, 2018).

Já a correlação positiva entre a variável contábil IDP, que apresenta os gastos do setor pessoal, e o nível de transparência, demonstra 0 interesse dos cidadãos em saber e/ou questionar informações desse cunho. Por exemplo, a pesquisa por numerários gastos com salários de políticos é grande, pois muitas pessoas se perguntam quanto ganha um político, haja vista o crescimento econômico pessoal destes agentes. Sendo esse um dos maiores questionamentos do cidadão/eleitor, o que consequentemente gera maior procura e motiva a maioria dos debates de interesse político, justifica-se a relação positiva entre a variável IDP e o nível de transparência, uma vez que os gestores buscam diminuir os custos de agência.

Assim, entende-se que a transparência deve ser utilizada como princípio de autoridade democrática, em que o cidadão possa participar da gestão estatal, cobrar eficiência e responsabilidade de seus gestores. Torna-se indispensável um papel mais presente da sociedade civil, que apresente hipóteses para soluções criativas e para o aumento do interesse social pelas questões políticas. A Teoria da Escolha Pública enfatiza a importância de regras institucionais que mantenham os governantes interessados pela sociedade; porém, não se faz suficiente sem a devida fiscalização e cobrança de seu cumprimento.

Tais evidenciações corroboram na mitigação da assimetria de informação existente entre os gestores públicos e a sociedade, demonstrando que o controle social exercido pelo povo, por meio de cobranças de transparência se faz presente. No entanto, alertase a necessidade de contínuo e perseverante interesse social nesta questão, além da evolução na preocupação quanto ao aprimoramento das informações prestadas por parte dos entes governamentais, tornando-as mais claras e condizentes à realidade.

\section{CONCLUSÕES}

O presente estudo teve como objetivo geral analisar se as 
condições socioeconômicas e contábeis dos 27 estados brasileiros influenciam no nível de transparência das informações de cunho público, divulgadas nos portais eletrônicos após a promulgação da Lei de Acesso à Informação, além de relacionar tais resultados aos pressupostos da teoria da Escolha Pública. A pesquisa foi delineada como descritiva quanto aos seus objetivos, documental quanto aos procedimentos e quantitativa quanto à abordagem do problema. Para sua realização, foi necessário o levantamento do nível de transparência dos estados, presente no Ranking Nacional da Transparência (TRANSP), sendo esse o índice correspondente à variável dependente. Para as variáveis independentes (condições socioeconômicas e índices contábeis), foram utilizados os dados disponíveis no site do IBGE e do FINBRA.

Após coleta das variáveis pertinentes, elas foram submetidas à técnica de regressão linear múltipla. Por conseguinte, pôde ser verificado que, dentre as variáveis socioeconômicas analisadas na pesquisa, a variável IFDM demonstrou resultado significativo quanto ao índice de transparência, indicando que quanto mais desenvolvido o estado, tendo como base emprego, renda, educação e saúde, maior é o nível de transparência eletrônica medida pela LAI.

Dentre as variáveis contábeis, percebeu-se que a condição financeira (IEOC), a capacidade de pagamento (ILIQ) e os gastos com pessoal (IDP) causam variação no nível de transparência dos estados brasileiros, sendo esta relação positiva. Isso demonstra que entes estaduais cuja condição financeira está adequada e que detêm capacidade de cumprir com os compromissos de pagamentos se mostram mais transparentes, uma vez que buscam sinalizar essa situação para a sociedade. A divulgação dos gastos com pessoal dos entes estaduais é de interesse de toda a sociedade, de modo que o governo se mostra transparente para diminuir os custos de agência.

Com tais constatações, foi possível efetuar o teste das hipóteses propostas para o estudo. A primeira afirma que existe influência positiva das variáveis socioeconômicas no nível de transparência, e, conforme observado nos resultados, o nível de desenvolvimento influencia positivamente a transparência do estado, permitindo a condição de aceite da H1. A segunda hipótese diz que há influência positiva entre as variáveis contábeis e o nível de transparência dos estados, e, observando as que apresentaram significância (IEOC, ILIQ, IDP), foi possível averiguar tal influência, de forma a dar condição de aceite também à H2.

O estudo contribui teoricamente para a continuidade dos estudos que envolvem a assimetria da informação do setor público. A contribuição prática da pesquisa se dá à comunidade, garantindo o direito à cidadania com o acesso a informações de cunho público, além da contribuição aos entes e/ou gestores, uma vez que podem verificar os resultados encontrados e ajustar seus portais para devida adequação à LAI.

Recomenda-se para pesquisas futuras um estudo aprofundado ao nível de transparência eletrônica do estado do Paraná, visando analisar a influência das características socioeconômicas e contábeis ao longo dos anos e a exigência pela LAI na publicação de suas informações. Recomenda-se aos cidadãos que continuem na busca por informações, que questionem e exijam explicações dos agentes públicos, exercitando, dessa forma, seu direito garantido em lei.

\section{REFERÊNCIAS}

Alcaide-Muñoz, L. A., Bolívar, M. P. R., \& Hernández, A. M. L. (2016) Transparency in governments: a meta-analytic review of incentives for digital versus hard-copypublic financial disclosures. The American Review of PublicAdministration, 47(5), 550-573.

Baldissera, J. F. (2018). Determinantes da Transparência Pública: um estudo em municípios brasileiros sob a ótica da teoria da escolha pública. Dissertação de Mestrado, Universidade Estadual do Oeste do Paraná Cascavel, PR, Brasil.

Baldissera, J., Walter, S., Fiirst, C., \& Dall' Asta, D. (2018). A Percepção dos Observatórios Sociais sobre a Qualidade, Utilidade e Suficiência da Transparência Pública dos Municípios Brasileiros. Sociedade, Contabilidade e Gestão, 13(3), 2018.

Behn, R. D. (1998). O novo paradigma da gestão pública e a busca da accountability democrática. Revista do Serviço Público, 49(4), 5-45.

Bellver, A., \& Kaufmann, D. (2005) Transparenting transparency: initial empirics and policy applications. World Bank Policy Research Working Paper, (forthcoming) (Washington). Disponívelem<http://siteresources.worldbank.org/INTEAPREGTOPRURDEV /Resources/573691

175901454225/seminar1_background_reading.pdf>Acessoem: 25/03/2017.

Beuren, I. M. (2008). Trajetória da construção de um trabalho monográfico em Contabilidade. In: BEUREN, Ilse Maria. (Org.). Como elaborar trabalhos monográficos em Contabilidade: teoria e prática (3a ed.). São Paulo: Atlas.

Buchanan, J. M. (1984). The theory of public choice - II. Michigan: University of Michigan Press.

Buchanan, J. M., \&Tullock, G. (1962). The calculus of consent (Vol. 3). Ann Arbor: Universityof Michigan Press.

Buchanan, J. M. (2003). Public choice: The originsand developmentof a research program. Champions of Freedom, 31, 13-32.

Cárcaba-García, A. I., \& García, J. G. (2010). Determinants of online reporting of accounting information by Spanish local government authorities. Local Government Studies, 36(5), 679-695.

Constituição da República Federativa do Brasil de 1988. (1998). Brasília. Recuperado em 11 dezembro, 2017, de https://goo.gl/gh99L8

Campello, C. A. G. B. (2003). Eficiência municipal: um estudo no estado de São Paulo. Tese de Doutorado, Universidade de São Paulo, São Paulo.

Carvalho, M. C M. (1988). Construindo o saber: metodologia científica. Campinas: Papirus

Cruz, C. F., Silva, L. M., \& Santos, R. (2010). Transparência da gestão fiscal: um estudo a partir dos portais eletrônicos dos maiores municípios do Estado do Rio de Janeiro. Contabilidade, Gestão e Governança, 12(3), 102-115.

Cruz, C. F. (2010.Transparência da gestão pública municipal: referenciais teóricos e a situação dos grandes municípios brasileiros. Dissertação de Mestrado, Universidade Federal do Rio de Janeiro, Rio de Janeiro.

Cruz, C. F.; Ferreira, A. S.; Silva, L. M.; \& Macedo, M. S. (2012). Transparência da gestão pública municipal: um estudo a partir dos portais eletrônicos dos maiores municípios brasileiros. Revista de Administração Pública, 46(1), 153-76.

Costa, G. P. C. L., Freire, F. S., Gartner, I. R., \& Clemente, A. (2013). As escolhas públicas orçamentárias federais no PPA 2008-2011: uma análise da perspectiva do modelo principal-agente. Revista de Administração Pública, 47(5), 1089-1116.

Dias, M. A. (2009). James Buchanan e a "Política" na escolha pública. Rev. Ponto e Vírgula, São Paulo, 6, 201-217.

Diniz, V. A história do uso da tecnologia da informação na gestão pública brasileira através do CONIP - Congresso de Informática Pública. In: Congresso Internacional Del CLAD sobre La Reforma Del Estado y de La Administración Pública, 10., Anais... Santiago, Chile, 2005

Diniz, J. A.; Martins, V. G.; \& Neves, A. C. D. (2015). Determinantes socioeconômicos da transparência fiscal. Anais do Congresso USP de Controladoria e Contabilidade. São Paulo, SP, Brasil, 15.

Frezatti, F., Rocha, W., \& Nascimento, A. R. (2009). Controle gerencial: uma abordagem da contabilidade gerencial no contexto econômico, comportamental e sociológico. São Paulo: Atlas.

Gil, A. C. (2008). Como elaborar projetos de pesquisa (4a ed.). São Paulo: Atlas.

Grimmelikhuijsen, S. G., \& Welch, E. W. (2012). Developing and testing a theoretical framework for computer-mediated transparency of local governments. Public administration review, 72(4), 562-571.

Hood, C. (2006). Transparency in historical perspective . New York: Oxford University Press.

Hood, C., \&Heald, D. (2006). Transparency: The key to better governance? 
New Yoek: Oxford University Press.

Instituto Brasileiro de Geografia e Estatística. Disponível em: $<w w w . i b g e . g o v . b r>$. Acesso em: 07/10/2017.

Lourençon, C. (2001). O orçamento municipal como elo de ligação entre o planejamento operacional e as finanças. Dissertação de Mestrado, Universidade Federal de Santa Catarina (UFSC), Florianópolis, SC, Brasil.

Macedo, J. J.; Corbari, E. C. (2009). Efeitos da lei de responsabilidade fiscal no endividamento dos municípios brasileiros: uma análise de dados em painéis. Revista Contabilidade \& Finanças, 20(51), 44-60.

Meijer, A. (2013). Understanding the complex dynamics of transparency. Public Administration Review, 73(3), 429-439.

Mello, G. R. (2009). Estudo das práticas de governança eletrônica: instrumento de controladoria para a tomada de decisões na gestão dos estados brasileiros. Tese de Doutorado, Faculdade de Economia, Administração e Contabilidade, Universidade de São Paulo, São Paulo, SP, Brasil.

Mueller, D. C. (1976). Publicchoice: A survey. Journalof Economic Literature, 14(2), 395-433.

Lei Complementar Federal № 101, de 4 de maio de 2000(2000). Estabelece normas de finanças públicas voltadas para a responsabilidade na gestão fiscal e dá outras providências. Portal da Legislação: Leis Complementares. $2000 . \quad$ Disponível em: <http://www.planalto.gov.br/ccivil_03/leis/LCP/Lcp101.htm>. Acesso em: 22/07/2017.

Lei Complementar Federal no 131, de 27 de maio de 2009 (2009). Disponível em: <http://www.planalto.gov.br/ccivil_03/leis/LCP/Lcp131.htm>. Acesso em: 22/07/2017

Lei $n^{\circ}$ 12.527, de novembro de 2011 (2011). Regula o acesso a informações previsto no inciso XXXIII do art. 5‥ Portal da Legislação: Leis Ordinárias. Disponível em: <http://www.planalto.gov.br/ccivil 03/ ato20112014/2011/lei/l12527.htm > Acesso em: 22/07/2017.

Pevorano, D. J. (2014). Manual de Metodologia Científica. Curitiba: Jeruá.

Pina, V., Torres, L., \&Acerete, B. (2007). Are ICTs promoting government accountability?: A comparative analysis of e-governance developments in 19 OECD countries. Critical Perspectives on Accounting, 18(5), 583-602.

Prado, O. (2009). Governo eletrônico, reforma do estado e transparência: o programa de governo eletrônico do Brasil. Tese de Doutorado, Escola de Administração de Empresas de São Paulo da Fundação Getúlio Vargas, São Paulo, 2009.
Prado, O., \& Garcia Loureiro, M. R. (2006). Governo eletrônico e transparência: avaliação da publicização das contas públicas das capitais brasileiras. Revista Alcance, 13(3), 355-372.

Porumbescu, G. A. (2015). Using transparency to enhance responsiveness and trust in local government: Can it work?. Stateand Local Governmen Review, 47(3), 205-213.

Richardson, R. J.(1989)Pesquisa social: métodos e pesquisa (2a ed.). São Paulo: Atlas.

Rothberg, D. (2008). Por uma agenda de pesquisa em democracia eletrônica. Opinião Pública, 14(1), 149-172.

Rückert, I. N., Borsatto, M. L., \& Rabelo, M. (2002). As finanças municipais e os gastos sociais no Rio Grande do Sul, 1995-99 (No. 50). Secretaria da Coordenação e Planejamento, Fundação de Economia e Estatística Siegfried Emanuel Heuser.

Santos, S. R. T., \& Alves, T. W. (2011). O impacto da Lei de Responsabilidade Fiscal no desempenho financeiro e na execução orçamentária dos municípios no Rio Grande do Sul de 1997 a 2004. Revista de Administração Pública, 45(1), 181-208.

Sartori, G. (2001). Homo Videns. Televisão e pós-pensamento. Bauru: EDUSC.

Silva, E. M.; Silva, E. M. Gonçalves, V., \& Murolo, A. C. (1997). Estatística: para os cursos de Economia, Administração e Ciências Contábeis (2a ed.). São Paulo: Atlas.

Souza, F. J. V., Barros, C. C., Araujo, F. R., \& Silva, M. C. (2013). Índice de transparência municipal: um estudo nos municípios mais populosos do Rio Grande do Norte. Revista de Gestão, Finanças e Contabilidade, 3(3), 94-113.

Stiglitz, J. E. (1999). On liberty, the right to know and public disclosure: the role of transparency in public life. Oxford: Oxford Amnesty Lecture.

Sturges, P. (2004). Corruption, transparency and a role for ICT?. International Journal of Information Ethics, 2(11), 1-9.

Tolbert, P. S., \&Zucker, L. G. (1998). A institucionalização da teoria institucional. In S. R. Clegg, C. Hardy, \& W. R. Nordy (Orgs.), Handbook de estudos organizacionais: modelos de análise e novas questões em estudos organizacionais (pp. 196-219). São Paulo: Atlas.

Tullock, G.,Seldon, A.,\& Brady L. G. (2002). Government failure: aprimer in public choice.Washington: Catho Institute.

Zuccolotto, R., \& Teixeira, M. A. C. (2014). As causas da transparência fiscal: evidências nos estados brasileiros. Revista Contabilidade \& Finanças, 25(66), 242-254. 